\title{
Research on the Problem of Strengthening Talent Training in Daqing City
}

\author{
Li Liu, Ye Liu, Hong Chang, Da Zhao* \\ Heilongjiang Bayi Agricultural University, Daqing, China \\ Email: *ndliuli@163.com
}

How to cite this paper: Liu, L., Liu, Y., Chang, H., \& Zhao, D. (2020). Research on the Problem of Strengthening Talent Training in Daqing City. Journal of Human Resource and Sustainability Studies, 8, 151-156. https://doi.org/10.4236/jhrss.2020.82009

Received: June 8, 2020

Accepted: June 26, 2020

Published: June 29, 2020

Copyright $\odot 2020$ by author(s) and Scientific Research Publishing Inc. This work is licensed under the Creative Commons Attribution International License (CC BY 4.0).

http://creativecommons.org/licenses/by/4.0/

(c) (i) Open Access

\begin{abstract}
As a typical oil resource-based city, Daqing has gathered a large number of technical talents after 60 years of development and construction. With Daqing entering the period of strategic reduction of crude oil production, in order to continuously promote the development of petrochemical industry, Daqing needs more types and levels of talents. Based on the analysis of the current situation of talents in Daqing City, this paper tries to solve the factors restricting the development of Daqing City, establish a more complete and standardized mechanism of talent training and operation, and provide useful reference and suggestions for the implementation of the strategy of strengthening the city with talents.
\end{abstract}

Keywords

Talent, Culture, Talent Strategy

\section{Introduction}

Daqing city is located in the northeast border area, with obvious geographical disadvantages, underdeveloped economy and weak attraction for talents. With the rapid development of coastal cities in the East and south, the phenomenon of Talents Outflow in the northeast area is increasingly prominent, and the situation is also grim. Talent training is more important for urban development. In terms of the current efficiency of the use of talents, the efficiency of the use of human resources in various organizations is not high, and talents have not been fully and effectively developed and utilized. We should give full play to the talent gathering effect of universities and scientific research institutes in Qingdao, make good use of existing talents, cultivate future talents and stabilize key talents. Grasp the favorable opportunity of Daqing's transformation and development, focus on continuous industrial development, build a high-level interdisciplinary and in- 
terdisciplinary talent team, mobilize the vitality of existing talents, activate the stock, and make talents play their role to the maximum extent.

\section{Daqing City Talent Development Strategy}

Daqing city talent strategy development can be roughly divided into four stages: one is the planned economy order. From the oilfield development to the end of the 1970s, the state has implemented a strict planning and distribution system for the distribution of human resources (Zhang, 2018). What kind of talents are needed and how many are needed? The state will make unified allocation according to the overall human resources stock and the local needs. Second, the stage of reform and opening up. By the 1980s, there were certain national planning restrictions at this stage, but both the government and the enterprises and institutions were responsible for absorbing talents. For a while, the graduates of new colleges and secondary schools and the old professional intellectuals moved from all directions to Daqing. In the management and use of talents, we have also adopted policies such as self training, going out training, and actively encouraging self-study to become talents, and initially established an incentive mechanism. Three is the oil economy leaps over the development stage. After entering the 1990s, the adjustment of talent strategy has been strengthened continuously, and the talent training, management and use have gradually transited to market economy. The rapid development of the petroleum industry and Daqing city has attracted talents mainly from the petroleum industry to gather in Daqing. Daqing also pays attention to the increasing investment in education, selects technical backbones to key universities for further training, and improves the comprehensive ability of talents from the selection of management personnel to the on-the-job training in developed areas. Fourth, the talent strategy stage of industrial transformation. With the transformation and development of Daqing City, the development of petroleum continuous industry has promoted the construction of talents team in Daqing city from petroleum industry to multi field talents (Wang, 2017). With the entrance of scientific research institutes and various economic entities, the talent structure of Daqing has gradually changed, and the development of strategic emerging industries has gradually become the focus. At the same time, the phenomenon of "Peacock Flying Southeast" has emerged (Ji, 2016).

\section{Current Situation of Talent Team in Daqing}

It is not difficult to see from the four stages of talent development in Daqing city that after entering the market economy, talent concentration changes with the development of urban economy, education and policy. In this change, the activity of high-end talent flow is the highest. Relatively speaking, the general talents who occupy the main body of urban development tend to be stable. Therefore, it is necessary to study the cultivation and development of all kinds of talents for urban development (Song, Fu, \& Zhang, 2015). 
By the end of 2018, the total number of talents in the city had reached 452,000, including 235,000 municipal talents, accounting for 51.9\%; 217000 talents in large enterprises directly under the central government, accounting for $48.1 \%$. Among the six talent teams in the city, there are 17,000 party and government talents, accounting for 3.8\%; 21,000 enterprise management talents, accounting for $4.6 \%$; 113,000 professional and technical talents, accounting for 25.0\%; 249,000 high skilled talents, accounting for 55.1\%; 47,000 rural practical talents, accounting for $10.4 \%$; and 5000 social work talents, accounting for $1.1 \%$.

\section{Analysis of the Problems and Reasons in the Training of Daqing Talents}

From the above data of total talents, we can see that due to the characteristics of the industry, the professional and technical talents in Daqing are mostly concentrated in education, health, scientific research and the enterprise system directly under the central and provincial governments. It is difficult to introduce talents, and the number of high-level talents is not large, especially the lack of leading talents, and the formation of high-level talent echelon. Compared with the developed cities in the south, the funds for talent training are still insufficient The coverage of talent training is still limited; the function of talent gathering is relatively weak, and the brain drain is relatively serious; due to identity, staffing and other reasons, the institutional barriers to the rational flow of talents still exist, and the innovation and entrepreneurship vitality of talents has not been fully released (Huang, 2014).

The above problems are not only affected by objective factors such as economic development level, external environment of location conditions, but also by internal management mechanisms such as talent training and talent development law (Song, 2011). External environmental factors include the policy environment favorable for talent flow due to the change of macro policies such as talent policy, wage and insurance policy, and the large-scale flow of talents towards the east coast due to the influence of economic factors, education environment, living environment, medical environment and cultural environment. At the same time, due to the long-term planned economy in the region where Daqing city is located, the management and use of talents, training and other reform means are relatively backward, which makes the sense of belonging of talents weak, and the development space and vitality are still weak.

\section{Countermeasures to Strengthen the Construction of Talent Training in Daqing City}

According to the report of the 19th National Congress of the Communist Party of China, talent is a strategic resource to realize national rejuvenation and win international competition. The state has successively implemented the talent training plan, highlighted the orientation of "high-quality and top-notch", not only geographically, but also more actively, more open and more effectively gathered talents. 


\subsection{Further Giving Play to the Leading Role of the Government}

In order to speed up the construction of talent team, Daqing city has issued the Interim Provisions on the implementation of several preferential policies for talents, covering all aspects of talent introduction, training, incentives, services, etc., which provides a strong guarantee for talent introduction and training, talent retention and entrepreneurship. As the main body of talent team construction, Daqing city should implement more effective policies, give full play to the role of baton and reservoir, introduce more direct and more attractive preferential policies for talents, combine the needs of enterprises and universities, introduce high-level and leading talents, improve the level of talent team, and at the same time, increase the number of young cadres in the form of temporary post, exchange and cross appointment To train and reserve talents for career development (Zhang, 2018).

\subsection{Increase the Development of Integration with Universities in Qingdao}

Colleges and universities are not only one of the important sources of scientific and technological innovation, but also one of the places where talents gather. The development of local economy and society cannot be separated from the scientific and technological support and intellectual support of colleges and universities. Through the establishment of a stable and perfect cooperation mechanism and policy support system between the city and University (Zhang, 2019), the resources can be released to the greatest extent, the role of Regional Universities in serving the local economic and social development can be brought into play, and the purpose of mutual promotion and win-win cooperation can be achieved by providing support for urban talent training.

\subsection{Optimize the Salary Structure of Talents}

Salary is an important driving force to promote the development of talents. A fair and reasonable salary distribution system is an important guarantee measure to mobilize the enthusiasm of talents and stabilize the talent team. The government should give full play to the compensation and incentive functions of salary, strive to provide necessary funds for the development of talents, provide salary rewards for all kinds of talents who have made outstanding contributions in all walks of life, and gradually establish a talent salary incentive mechanism in line with the characteristics of the industry and enterprises.

\subsection{Increase Talent Skills Training}

The government should give full play to the role of the existing training resources, mainly including: vocational ability training to ensure that high skilled personnel complete their work in the corresponding posts; innovative ability training to keep talents constantly playing their talents and realize the maximization of personal value; workplace adaptability training, according to the characteristics of the post, can make use of the latest theoretical knowledge and practical operators of the profession and the ability of law (Song, Fu, \& Zhang, 2015). 


\subsection{Strengthen System Construction and Establish Long-Term Mechanism of Talent Training}

Fully understand the key role of talent team construction in the development of Daqing City, practically strengthen the construction of talent team, give full play to the enthusiasm, initiative and creativity of talents, effectively perform various responsibilities of talents, and promote the development of the city. We will form a perfect system in the key links of talent planning and design, selection and training, use and incentive, strive to establish and improve the system of talent team construction with training, evaluation, use and incentive as the main content, establish and improve the mechanism of talent assessment and evaluation and talent incentive, and promote the construction of talent team (Wang, 2019).

With the progress and development of the times, human resources, especially high-level talents, have become the most important factor to support the core competitiveness of all walks of life. Daqing is now facing the transformation of resource-based cities, in order to take a good road of transformation and development of resource-based cities, the talent factor is the most core factor. However, the cultivation of talents cannot be realized overnight. We must take certain measures to innovate the mechanism of talent introduction, cultivation and use, and vigorously implement the strategy of strengthening the city with talents, so as to improve the core competitiveness of Daqing city.

\section{Funding}

Philosophy and Social Science Foundation of Daqing (CN) (Award Number: DSGB2019058).

Teaching reform project of higher education in Heilongjiang Province (Award Number: GJZ201301072).

\section{Conflicts of Interest}

The authors declare no conflicts of interest regarding the publication of this paper.

\section{References}

Huang, L. L. (2014). Research on the Current Situation and Countermeasures of Human Resources Development in Daqing City. Business Economy, 23, 81-83.

Ji, L. H. (2016). Thoughts on Implementing the Strategy of Talent Priority Development in Daqing City. Daqing Social Sciences, 1, 22-23

Song, H. L., Fu, Y., \& Zhang, Y. (2015). Study on the System and Mechanism of Talent Gathering in Daqing. Daqing Social Sciences, 4, 33-36

Song, X. S. (2011). Design and Implementation of Skills Appraisal System for High Skilled Talents in Shengli Oilfield. Master Thesis, Chengdu: University of Electronic Science and Technology.

Wang, D. (Association of Social Science Circles of Daqing City) (2019). Countermeasures on Increasing the Efforts of Talent Introduction in Daqing City. Daqing Social Science, 6, 73-74. 
Wang, S. (2017). Study on the Economic Transformation Strategy of Daqing Resource-Based City. Master Thesis, Harbin: Harbin Engineering University.

Zhang, G. L. (2019). Daqing Talent Research on Development Strategies. National Circulation Economy, 3, 93-94.

Zhang, X. (2018). Research on Talents in Oil Resource-Based Cities: Taking Daqing City in Heilongiiang Province as an Example. Modern Economic Information, 18, 75. 